OPEN ACCESS

Edited by:

Cheng Yong Tan,

The University of Hong Kong,

Hong Kong

Reviewed by:

Ming Lui,

Hong Kong Baptist University,

Hong Kong

Angelica Moè

University of Padua, Italy

*Correspondence:

Jacqueline P. Leighton

jacqueline.leighton@ualberta.ca

Specialty section:

This article was submitted to

Educational Psychology,

a section of the journal

Frontiers in Education

Received: 23 January 2021

Accepted: 02 March 2021

Published: 25 March 2021

Citation:

Liu Y and Leighton JP (2021)

Parental Self-Efficacy in Helping Children Succeed in School Favors

Math Achievement.

Front. Educ. 6:657722.

doi: 10.3389/feduc.2021.657722

\section{Parental Self-Efficacy in Helping Children Succeed in School Favors Math Achievement}

\author{
Ye Liu' ${ }^{1}$ and Jacqueline P. Leighton ${ }^{2 *}$ \\ ${ }^{1}$ Department of Psychology, Zhongshan Hospital, Fudan University, Shanghai, China, ${ }^{2}$ Faculty of Education, Centre \\ for Research in Applied Measurement and Evaluation, University of Alberta, Edmonton, AB, Canada
}

Parents play an important role in children's academic achievement. The purpose of the present study was to explore the internal structure of an established parent survey and to investigate the relationships among different aspects of parental involvement in predicting children's mathematics achievement. The study involved secondary data from 139 parents and math achievement scores of 121 elementary school-aged children. Guided by Hoover-Dempsey and Sandler's Revised Parent Involvement Process model, a Principal Component Analysis with direct oblimin rotation was conducted on the parent survey, followed by path analysis to predict children's math achievement. Five principal components were retained. Standardized results of the path analysis indicated that parental self-efficacy had the largest direct effect on children's math achievement. Moreover, parental self-efficacy was favored directly by parental perceptions of specific school invitations to become involved. These findings shed light on the interplay between parental involvement and children's achievement and underscore the importance of school-family collaboration, which can potentially link to parental self-efficacy.

Keywords: parental involvement, academic achievement, parental self-efficacy, mathematics, Hoover-Dempsey and Sandler parental involvement model

\section{INTRODUCTION}

Mathematics achievement is an integral part of overall academic achievement. Children's early math achievement can strongly predict later academic achievement, financial success, and future career choices (e.g., Duncan et al., 2007). Children's math achievement can be directly or indirectly influenced by both internal and external factors, such as academic self-concept, cognitive abilities, popularity among peers and perceived support from teachers at school (Niehaus et al., 2012; Veas et al., 2015). Focusing on math achievement specifically, school practices that promote parental involvement in helping children learn mathematics at home have been found to be related to students' improved performance on standardized math achievement tests (Sheldon and Epstein, 2005). For example, activities such as parents providing home-based support for learning and celebrating student accomplishments have been found to be crucial for enabling positive mathematics outcomes in children (Ginsburg-Block et al., 2010).

Since parents play an important role in their children's growth and learning, the goal of this research was to investigate parental involvement in their children's education, and specifically the effects of this involvement on children's math achievement. Moreover, this research focused on examining the ways in which two valuable scholarly tools-a well-known research survey and 
a theoretical model-could be used in combination to further understanding of parental involvement in children's achievement. Examining the ways in which survey tools and theoretical models work in tandem can contribute to the evidentiary support of both the tool and the model, and provide insights into our own "blind spots."

The present study focused on math achievement for three reasons. First, math achievement can play a prominent role in facilitating children's pursuit of a breadth of educational opportunities in science, technology, engineering and mathematical (STEM) fields. Second, compared to language arts achievement, math achievement can generally be more objectively graded and quantified since there are standard answers. Third, given the sample size requirements for the multivariate analysis conducted in the present study, focusing on a single academic outcome was a necessary constraint. For these three reasons, the study focused solely on math achievement; however, future research should investigate whether the work presented here applies to other academic disciplines. Two research questions guided the study: (1) What is the structure of the Sheldon and Epstein (2007) Parent Survey of Family and Community Involvement in Elementary and Middle Grades in the sample of parents included in the present study? (2) What is the most parsimonious path model for explaining relationships among variables such as parental perceptions, self-efficacy and involvement on children's math achievement.

\section{BACKGROUND AND CONTEXT}

There are many definitions of parent involvement in children's schooling and ways to operationalize its practice (Hornby, 2011). Some researchers define parent involvement concretely as comprising a wide range of parental activities/behaviors both at home and at school that are relevant to children's learning in school; others define parental involvement generally as the investment parents make either behaviorally or financially in their children's education (Hoover-Dempsey and Sandler, 1997; LaRocque et al., 2011). Hornby (2011) identified the six most common models of parental involvement as including a protective, expert, transmission, curriculum enrichment, consumer, and partnership model of parental involvement in children's schooling. Although it is beyond the scope of the present paper to review all these models, a number of variables distinguish them. For example, one of the key variables in these models is how parents interact with the school system. In the protective and expert models, parent interaction is minimal because teachers are viewed as the experts and parental involvement is defined as ensuring children follow expectations from the school. In contrast, in the curriculum enrichment and partnership models, parents have more interaction with the school system because they are viewed by school officials as not only experts in their children but also as resources for how to help in their children's uptake of the curriculum. Still others conceptualize parental involvement as including more than how parents work with school officials or invest resources into their children's education. Deci and Ryan's (2008) Self-Determination
Theory includes the extent to which parental attributes foster encouragement in their children to be active, creative agents in their own learning. For example, Liu et al. (2013) showed that parental involvement moderated children's self-directed motivation, which in turn influenced their creativity in thinking. Many other studies have shown that parental practices can either facilitate or hinder children's achievement depending on whether the parents foster autonomy or control in their children, respectively (e.g., Cooper et al., 2000; Dumont et al., 2012; Moè et al., 2020).

One of the most comprehensive accounts of parental involvement is the revised Parental Involvement Process (R-PIP) model by Hoover-Dempsey and Sandler (2005; see also 1995, 1997 for earlier versions). This study used the R-PIP model as its guiding framework because it integrates the two dimensions of parental involvement that have been identified as importantparental interaction with the school and the personal attributes parents possess to help their children become active agents in their learning (Joussemet et al., 2008). As shown in Figure 1, the R-PIP model outlines a variety of hypothesized relationships related to parental involvement in children's education. The R-PIP model consists of five levels of hypothesized influences. The levels are described in some detail as the R-PIP model served as the guiding framework in the present study.

\section{The Revised Parental Involvement Process (R-PIP) Model}

Level 1 of the model includes three broad variables comprising parental motivational beliefs, perceptions of invitations for involvement, and perceptions of life context. Level 1 serves as the basis of the model. Each of these three broad variables involves finer-grained definitional variables. For example, parental motivation beliefs include (a) parental construction (beliefs) about their roles to become involved in their children's education, and (b) parental self-efficacy for helping their child succeed in school. The variables at Level 1 are hypothesized to contribute to parental involvement behaviors at Level 2 .

Level 2 parental involvement behaviors can include homebased or school-based involvement actions, which would involve mechanisms such as encouraging the child, modeling academic-related behaviors for the child, reinforcing the child's activities, and instructional activities with the child. Level 2 behaviors in turn influence Level 3 variables such as children's perceptions of parental involvement. Children's perceptions of parental involvement include children's perceptions of parental encouragement, modeling, reinforcement and instructional activities. Level 3 variables are hypothesized to influence children's underlying attributes for achievement at Level 4; for example, children's academic self-efficacy and intrinsic motivation for learning at school. Finally, Level 4 variables are hypothesized to influence children's academic achievement at Level 5, reflecting one of the final outcomes of the parental involvement process.

The R-PIP model was used as a guiding framework for the present study. However, not all levels of the R-PIP model were able to be included in this research. In particular, only Levels 


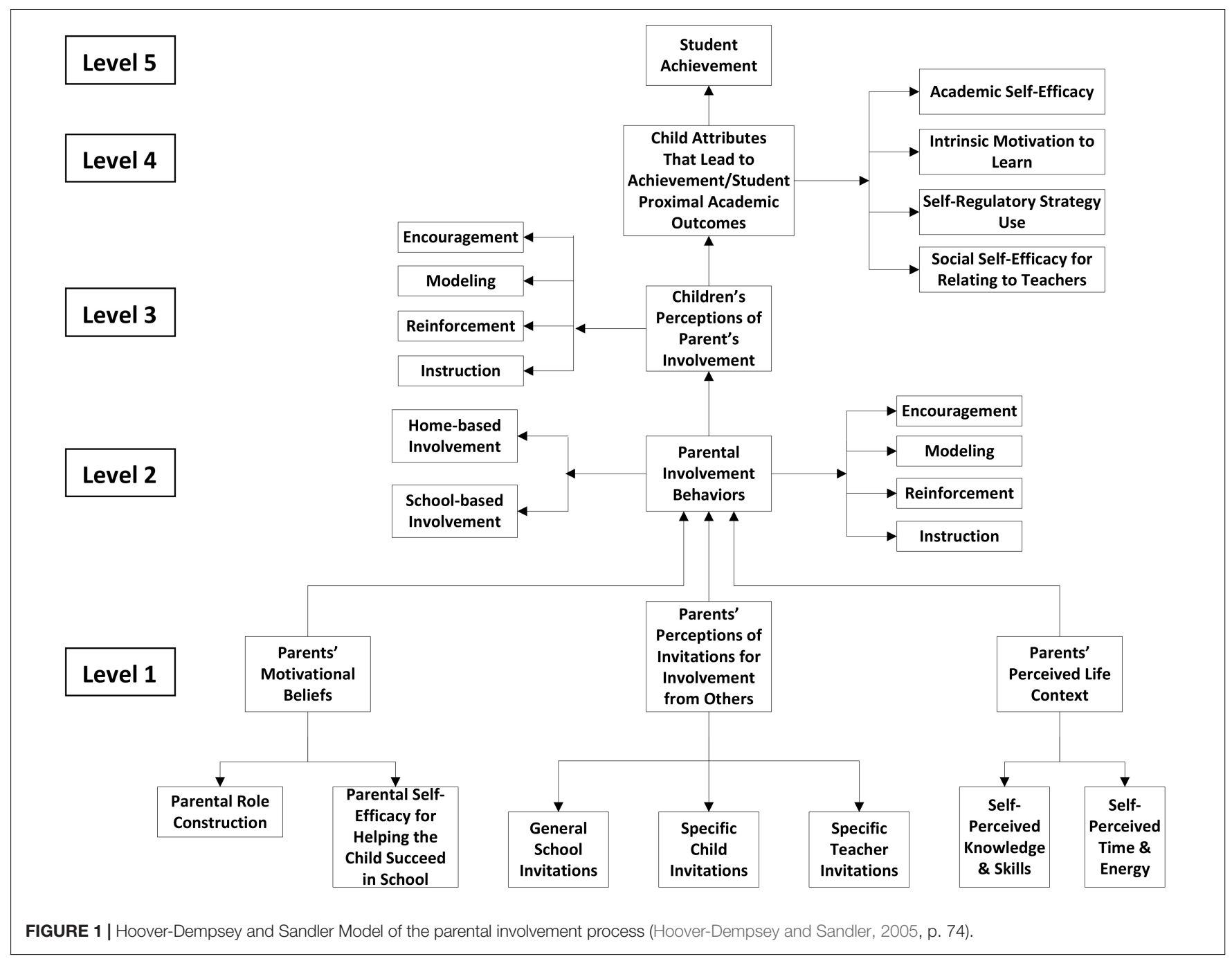

1,2 , and 5 were included given constraints in data collection. One constraint involved the use of Sheldon and Epstein's (2007) Parent Survey of Family and Community Involvement in the Elementary and Middle Grades. This survey probes parental selfreport data at levels 1 and 2 of the R-PIP model. In addition, data at Level 3 were not collected because these would have required surveying children's perceptions of parental involvement along with children's personal attributes in academic achievement. Obtaining such data required a level of time and intrusion in family participation that school administrators discouraged authors from pursuing. Thus, the majority of data collected in the present study originated from parental responses to Sheldon and Epstein's (2007) survey, which probes Levels 1 and 2 of the R-PIP model. With parental consent, Level 5 data on children's academic outcomes were released by school administrators. Each of Levels 1, 2, and 5 is discussed in detail in the following paragraphs.

\section{Level 1 of the R-PIP Model}

Overall, the R-PIP model (Hoover-Dempsey and Sandler, 1995, 1997, 2005) suggests that a series of parental beliefs and perceptions at Level 1 come into play in whether and how parents become involved in their children's schooling. The first main variable at Level 1 is parental motivational beliefs. Parental motivational beliefs are defined as parental role construction beliefs and parental self-efficacy for helping a child succeed in school. Specifically, parental role construction beliefs are defined as "parents' beliefs about what they should do in relation to their children's education" (Hoover-Dempsey and Sandler, 2005, p. 14, italics in original). Role construction beliefs can change with experience as parents interact with others during their children's school education. In contrast, parental self-efficacy is defined as "parents' beliefs about their personal ability to make a difference in the child's educational outcomes through their involvement" (Hoover-Dempsey and Sandler, 2005, p. 14). Parental selfefficacy for helping children succeed in school likely emerges from a variety of sources (Bandura, 1997) such as parents' direct and indirect (vicarious) educational experiences, their own relationships with teachers during childhood, discussions with other parents, interactions with children generally, and even their emotional readiness for their role as caregivers (Coleman and Karraker, 1998). 
Parental self-efficacy is a critical factor that determines the goals parents choose for themselves and how persistent they are in working toward those goals (Bandura, 1997). In hypothesizing the direction of influence between role construction beliefs and self-efficacy beliefs, it is unknown which of these variables comes first given the relative lack of research in how parental beliefs are related. Indeed, the R-PIP model does not offer specific guidance in this respect because it does not include directional relations among variables within levels. Consequently, one of the goals of the present study was to explore the directional influences between variables within levels of the R-PIP model, and in so doing, contribute to the existing literature about such relationships.

The second variable at Level 1 is parental perceptions of invitations for involvement from others. This second variable is defined by parents' perceptions of general school invitations, specific child invitations, and specific teacher invitations. The term "invitation" in the R-PIP model is to refer to actions that make parents feel needed, valued and welcomed (HooverDempsey and Sandler, 2005). For example, parents who perceive the school to be inclusive would be expected to have beliefs that promote their participation in children's schooling. Likewise, parents who perceive their child as wishing or needing their involvement would be more likely to see this as an invitation to become involved; as well, parents who receive requests from teachers for meetings or volunteering would see these as invitational gestures (Hoover-Dempsey and Sandler, 1995, 2005). Positive associations have been found between parental perceptions of invitations for involvement and parental selfefficacy regarding their children's education (Sheldon, 2002; Shumow and Lomax, 2002).

The third variable at Level 1 is parents' perceived life context. This third variable is defined by parents' self-perceived knowledge and skills and self-perceived time and energy (Hoover-Dempsey and Sandler, 1995, 2005). Ethnicity, stress and socio-economic status (SES) can alter parental involvement in their children's academic achievement (Hill et al., 2004; Lee and Bowen, 2006; Sibley and Dearing, 2014). For example, higher-SES parents have generally been found to have higher levels of involvement in children's education (Hill et al., 2004; Lee and Bowen, 2006).

\section{Level 2 of the R-PIP Model}

The second level of the model includes one main variableparental involvement behaviors. Parental involvement behaviors can occur in the home (e.g., helping a child with homework) or at school (e.g., volunteering to help with a class field trip). Parental involvement behaviors take different forms within the home or at school. For example, parents can involve themselves by verbally encouraging children, modeling interest and timemanagement strategies to their children, reinforcing children's completion of school tasks, and directly instructing children during homework time. Although previous research has shown parental involvement to be positively associated with children's academic achievement (Fan and Chen, 2001; Castro et al., 2015; Ma et al., 2016; Boonk et al., 2018), the strength of the relationship varies depending on the types of parental involvement and achievement measures considered (Wilder, 2014). For example, the relationship between home-based parental involvement (e.g., with homework among elementary school students) does not consistently show a positive association with children's achievement (Driessen et al., 2005; Tam and Chan, 2009; Carmichael and MacDonald, 2016). In addition, results of parents' school-based involvement with elementary children's academic achievement has also led to mixed results (McBride et al., 2009; Stright and Yeo, 2013; Johnson and Hull, 2014).

\section{Level 5 of the R-PIP Model}

The main variable at Level 5 of the model is student achievement. Hoover-Dempsey and Sandler (2005) originally defined this variable as involving "student grades and student performance on standardized tests of achievement as the two summary measures" (p. 34). However, student achievement can be operationalized in a variety of ways depending on the student learning and assessment products that are considered.

\section{PRESENT STUDY AND OBJECTIVES}

The present study focused on Levels 1, 2, and 5 of the R-PIP model. The aim was to measure select variables at these levels using a previously developed survey called the Parent Survey of Family and Community Involvement in Elementary and Middle Grades (Sheldon and Epstein, 2007) ${ }^{1}$. The Sheldon and Epstein (2007) survey was developed in the US and has been used for research purposes for over a decade, yielding acceptable reliability estimates (Epstein et al., 2019; see text footnote 1). However, the authors were not able to find any reliability studies with the sample of parents from the geographical location (Canada) of the present study, and no dimensionality studies. Hence, the first objective was to evaluate the internal structure of the survey with the participants in the present study, and determine the components of parental involvement that could be reliably used in predicting children's mathematics achievement to build on previous research (Fan and Chen, 2001; Sheldon and Epstein, 2005; Ginsburg-Block et al., 2010; Carmichael and MacDonald, 2016). Following an investigation of the underlying components of the Sheldon and Epstein (2007) survey, the second objective was select key components that operationalized key variables of the R-PIP model, and evaluate their association to children's mathematics achievement. Essentially, this objective was met using path analysis, which permitted examination of the effects of parental involvement factors on elementary children's math achievement.

\section{MATERIALS AND METHODS}

\section{Participants}

The data used in the present study originated from a previous project designed to investigate the relationship between a specific pedagogical approach employed in a public elementary school and students' learning outcomes (Leighton, 2013;

\footnotetext{
${ }^{1}$ http://nnps.jhucsos.com/
} 
Leighton et al., 2018). The original data were collected in 2012 from a convenience sample of 25 teachers, 262 students, and 139 parents associated with the school. Almost all students in the school participated. There were no specific inclusionary criteria for teachers, students or parents who participated in the original study.

Of the 25 teachers participating in the original study, two teachers from each of Grades 1, 2, 4, 5, and 6 participated in the original study. Four teachers from Grade 3 participated as well, and 2 Educational Assistants. The original participating students $(n=262)$ ranged in age from 6 to 12 years, with a mean age of 8.4 years $(S D=1.80)$. The sample included 123 boys (46.9\%) and 124 girls (47.3\%), with 15 students not disclosing their gender $(5.7 \%)$. For the present study, data from only 121 students [55 boys (45.5\%), 65 girls (53.7\%), and 1 unspecified], were included in the analyses as these were the only students who could be linked with parental survey data. Almost $70 \%$ of participating students identified as European-White $(n=83)$, with another $10 \%(n=14)$ reporting South Asian ethnicity. The remaining $20 \%$ of students identified their ethnicity as Black or Middle Eastern/Arab, or preferred to not disclose their ethnic background. The vast majority of the 121 students indicated speaking English at home $(n=103 ; 85.1 \%)$.

Among the participating parents, close to $90 \%$ were female primary caregivers $(n=122$ of 139$)$, with the remaining $10 \%$ identifying as male caregivers. Thirty-three percent of participating parents had earned a college diploma $(n=46)$, and $45 \%(n=62)$ completed a graduate degree or obtained graduate credits. Most parents reported speaking English at home (85.6\%). The ethnic background reported by participating parents was similar to that reported by students. Almost $70 \%$ of parents identified as European-White ( $n=96$ of 139 ), with just under $12 \%$ identifying as South Asian ( $n=16$ of 139 ). The remaining $18 \%$ of parents identified as Black, Latino/Latin American or other, which often reflected Middle Eastern/Arab origin.

\section{Procedures}

Procedures of the original data collection are outlined by Leighton (2013). All procedures performed in the original study, involving human participants, were conducted in accordance with the ethical standards of the institutional research committee, the 1964 Helsinki declaration and its later amendments or comparable ethical standards. In particular, a research assistant with 20 years of experience assisted the second author to present the study to a local Kindergarten-Grade 6 Charter School in a large metropolitan city. The superintendent, principal and teachers of the school agreed in the importance of the study and, using the school Newsletter, promoted participation in the study for all parents of children attending the school. Interested parents who wished to learn more about the study contacted the school principal confidentially and were sent information from the second author. Those parents who wanted to participate in the study indicated their interest to the principal of the school, and were sent a study package over surface mail. The study package contained a consent form, surveys and a return-postage envelope with instructions to submit the completed surveys confidentially (in a sealed envelope) to the school principal. The research assistant collected all confidentially sealed envelopes from the school principal. The research assistant replaced participant names with identification numbers and entered all the survey responses into a database ensuring the anonymity of participants.

\section{Materials and Measures}

The present study included two global measures. First, the Parent Survey of Family and Community Involvement in Elementary and Middle Grades (Sheldon and Epstein, 2007). Second, children's mathematics achievement grades as provided by school administrators.

\section{Sheldon and Epstein (2007) Survey}

The complete Sheldon and Epstein (2007) survey is described briefly here and can be accessed at http://nnps.jhucsos.com/. The survey contains 10 sections (including a demographic section) with approximately 110 closed items designed to measure family attitudes related to school, practices of involvement, desired community services, homework activities, family structure and experiences. There are also some open-ended questions. According to Sheldon and Epstein (2007), internal consistency estimates for the survey range from 0.65-0.96. Eight of the 10 sections are above 0.8 but below 0.9 .

For purposes of the present research, only 5 sections ( 55 items) of Sheldon and Epstein's (2007) survey were considered to reflect variables at Levels 1 and 2 of the R-PIP model. The 5 sections of the parent survey, corresponding items and scales are shown in Table 1. A mapping of the 5 survey sections with R-PIP model variables is shown in Figure 2. As illustrated in Figure 2, section 1 of the parent survey "Perceptions of Teacher-Parent Contact" mapped on to the R-PIP Level 1 variable "Perceptions of Specific Teacher Invitations." Section 2 of the parent survey "Parents' Attitudes About the School and Teachers in General" mapped on to the R-PIP Level 1 variable "Perceptions of General School Invitations." The remaining mapping of sections 3 , 4, and 5 of the parent survey are shown in Figure 2.

Although the parent survey sections could be mapped to R-PIP model, it is important to note that the survey did not cover all R-PIP model variables at specific levels. For example, the following three R-PIP model variables at Level 1 were not reflected in the parent survey: Parents' self-perceived knowledge and skills, parents' self-perceived time and energy, and perceptions of specific child invitations. Moreover, even when a survey section could be mapped to a variable in R-PIP model, the items in the survey section did not necessarily reflect all aspects of that specific R-PIP model variable. For example, survey section 3 "Parental Involvement Behaviors" mapped well to the R-PIP Level 2 variable "Parental Involvement Behaviors." However, the survey items did not include measures of parental encouragement or modeling behaviors. Instead, the items included mostly parental questioning and instructional behaviors.

With permission from the publisher, slight changes to the wording of some items and probes were made to maximize the clarity of the items for the parents in this study. For example, a question was altered to reflect the proper name of meetings at the school instead of using the American term "PTA." A final section requesting demographic information about the family was also included in the survey. 
TABLE 1 | Descriptive analysis of all survey items.

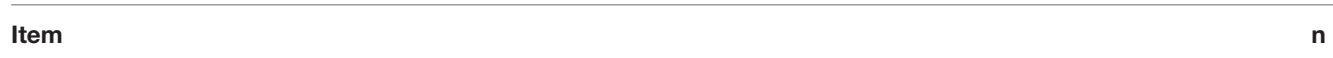

n

$M$

$S D$

[SECTION 1- Perceptions of teacher-parent contact] 16 Items My child's teacher or someone at the school... Response Scale: 1-Well, 2-OK, 3-Poorly, and 4-Never

1a. Helps me understand my child's stage of development. *

137

1b. Tells me how my child is doing in school. *

1c. Ask me to volunteer at the school. *

1d. Explains how to check my child's homework.

1e. Sends home news about things happening at school.

1f1. Tells me what skills my child needs to learn in: math. *

1f2. Tells me what skills my child needs to learn in: reading/language arts. *

1f3. Tells me what skills my child needs to learn in: science. *

1g. Provides information on community services that I may want to use with my family. *

1h. Invites me to School Council meetings. *

1i. Assigns homework that requires my child to talk with me about things learned in class.

1j. Invites me to a program at the school.

$1 \mathrm{k}$. Asks me to help with fund raising.

11. Has a parent-teacher conference with me.

$1 \mathrm{~m}$. Includes parents on school committees, such as curriculum, budget, or improvement committees. *

1n. Provides information on community events that I may want to attend with my child.

[SECTION 2-Parents' attitudes about the school and teachers in general] 4 Items How much do you agree

or disagree with the following statements about your child's school and teachers? Response Scale:

1-Strongly Agree, 2-Agree, 3-Disagree, 4-Strongly Disagree

2a. This is a very good school. *

2b. I feel welcome at the school. *

2c. I get along well with my child's teacher(s). *

2d. The teachers at this school care about my child. *

[SECTION 3-Parents' involvement behaviors] 17 Items How often do you. . . Response Scale:

1-Everyday/Most Days, 2-Once a Week, 3-Once in a While, 4-Never

3a. Read with your child? *

3b. Volunteer in the classroom or at the school?

3c. Work with your child on science homework? *

3d. Review and discuss the schoolwork your child brings home? *

3e. Help your child with math? *

3f. Visit your child's school? *

3g. Go over spelling or vocabulary with your child? *

3h. Ask your child about what he/she is learning in science? *

3i. Talk to your child's teacher? *

3j. Ask your child about what he/she is learning in math? *

3k. Help your child with reading/language arts homework? *

3l. Help your child understand what he/she is learning in science? *

$3 \mathrm{~m}$. Help your child prepare for math tests? *

$3 n$. Ask your child how well he/she is doing in school?

3o. Ask your child to read something he/she wrote?

3p. Go to a school event (e.g., sports, music, drama) or meeting?

3q. Check to see if your child finished his/her homework? *

[SECTION 4-Parents' beliefs about their responsibility in children's education] 10 Items It is a parent's responsibility to... Response Scale: 1-Strongly Agree, 2-Agree, 3-Disagree, 4-Strongly Disagree

4a. Make sure that their child learns at school. *

4b. Teach their child to value schoolwork. *

4c. Show their child how to use things like a dictionary or encyclopedia.

4d. Contact the teacher as soon as academic problems arise. *

4e. Test their child on subjects taught in school.

4f. Keep track of their child's progress in school. *

$4 \mathrm{~g}$. Contact the teacher if they think their child is struggling in school.

9

$\begin{array}{ll}1.53 & 0.71 \\ 1.27 & 0.52 \\ 1.60 & 0.68 \\ 1.32 & 0.55 \\ 2.06 & 0.92 \\ 1.30 & 0.55 \\ 1.11 & 0.33\end{array}$


TABLE 1 | Continued

\begin{tabular}{|c|c|c|c|}
\hline Item & $\mathbf{n}$ & $M$ & $S D$ \\
\hline 4h. Show an interest in their child's schoolwork. & 139 & 1.12 & 0.33 \\
\hline 4i. Help their child understand homework. & 139 & 1.30 & 0.56 \\
\hline 4j. Know if their child is having trouble in school. * & 138 & 1.14 & 0.37 \\
\hline \multicolumn{4}{|c|}{$\begin{array}{l}\text { [SECTION 5-Parents' beliefs about their capability in helping with children's education] } 8 \text { Items How much } \\
\text { do you agree or disagree with the following statements? Response Scale: 1-Strongly Agree, 2-Agree, } \\
\text { 3-Disagree, 4-Strongly Disagree }\end{array}$} \\
\hline 5a. I know how to help my child do well in school. * & 138 & 1.76 & 0.60 \\
\hline 5b. I never know if I'm getting through to my child. * & 138 & 3.06 & 0.72 \\
\hline 5c. I know how to help my child make good grades in school. * & 137 & 1.80 & 0.67 \\
\hline 5d. I can motivate my child to do well in school. * & 138 & 1.77 & 0.66 \\
\hline 5e. I feel good about my efforts to help my child learn. * & 138 & 1.59 & 0.62 \\
\hline 5f. I don't know how to help my child on schoolwork. * & 138 & 3.32 & 0.70 \\
\hline 5g. My efforts to help my child learn are successful. * & 138 & 1.70 & 0.59 \\
\hline 5h. I make a difference in my child's school performance. * & 138 & 1.60 & 0.61 \\
\hline
\end{tabular}

Items that were labeled with an asterisk $\left(^{*}\right)$ were retained following the PCA.

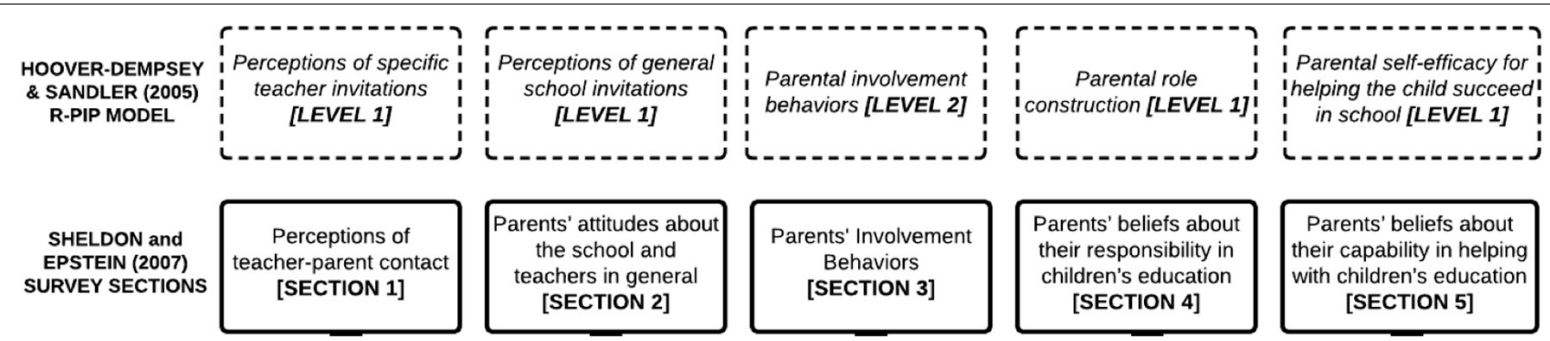

FIGURE 2 | Mapping of Hoover-Dempsey and Sandler (2005) R-PIP model in top row, Sheldon and Epstein (2007) survey section in top row.

\section{Children's Mathematics Grades}

The parent survey was administered and completed in November, 2012. In December 2012, children's mid-term report-card grades were collected from the school principal. According to school assessment practices, children's academic achievement was operationalized by teachers' classroom-based assessments in Mathematics. Teachers' classroom-based assessments included in-class assignments, homework, quizzes, and end-of-unit tests. Student assessment outcomes were formalized using the school's five-point system (Leighton et al., 2018). For example, a score of 5 reflected a student performance average of 90-100\% (excellent). A score of 4 indicated an average of $80-89 \%$ (very good) and a score of 3 demonstrated an average of $65-79 \%$ (good). A score of 2 reflected an average of 50-64\% (improvement of achievement was needed) and a score of 1 represented an average of below 50\%, which signaled a need for a formal improvement plan. Large-scale standardized test scores were not used because they were only available for Grade 3 students.

\section{Data Analyses}

Since no previous studies had examined the internal structure of the Sheldon and Epstein (2007) parent survey in the Canadian parent population included in the present study, the first objective aimed to evaluate the internal structure of the survey. The second objective was to conduct a path analysis of components of parental involvement to predict children's mathematical achievement. All survey items were reverse coded so that higher ratings reflected a higher level of the variable being measured. Bartlett's Test of Sphericity and the Kaiser-Meyer-Olkin test were used to examine the appropriateness of the survey data for structure detection (Bartlett, 1950; Kaiser, 1970). Due to a parent sample size of 139, Principal Component Analysis (PCA) using SPSS 21.0 was used for data reduction and to identify components of the survey. The direct oblimin method of rotation was used as the components were expected to be correlated and this method can be applied even when the factors are correlated but not significantly (Beavers et al., 2013).

After conducting the PCA, scale scores for each component were calculated. Scale scores were calculated by taking the average of item ratings that loaded on a particular component. Path analysis using Mplus v. 7.11 (Muthen and Muthen, 2013) was then conducted based on the scale scores to examine the relations among the relevant components of parental involvement for predicting children's mathematics achievement. Path analysis was chosen instead of structural equation modeling because of the small sample size $(n=139)$. Researchers have suggested sample sizes of no less than 200 for structural equation modeling (Kline, 2016).

Path analysis required data from parents and children to be cross-linked. Complete data were available from only 121 parent-child dyads. A few parents did not consent to reveal their children's achievement data, but they consented to have their 
own data included in the path analysis; thus, their children's data were coded as missing. The normality assumption of scale scores and children's math achievement scores was verified using the Kolmogorov-Smirnov test and the Shapiro-Wilk's test in SPSS. All components were found to be negatively skewed and revealed a departure from normality in distribution $(p<0.01)$. However, maximum likelihood with robust standard errors estimation (MLR) was used to handle the non-normal data in Mplus v. 7.11. MLR is robust to violation of the normality assumption (Wang and Wang, 2012).

In the process of conducting PCA, missing data were addressed in SPSS 21.0 using the listwise deletion method. Listwise deletion method was used instead of pairwise deletion because the latter approach can lead to non-positive definite correlation matrices, causing estimation problems for subsequent multivariate analyses (Enders, 2010). Path analysis cannot be conducted in SPSS so it was done in Mplus v. 7.11 using fullinformation maximum likelihood (FIML) with robust standard error estimation procedures to address missing data (Muthen and Asparouhov, 2002; Muthen and Muthen, 2013). Indirect effects of possible mediating components in the path model were tested using the bias-corrected (BC) bootstrap approach with confidence interval (estimator $=$ maximum likelihood, with 1000 bootstrap; Geiser, 2010). This is elaborated in the Results section.

\section{RESULTS}

\section{Principal Component Analysis (PCA)}

To verify the adequacy of the data for PCA, the KMO test (Kaiser, 1970) and Bartlett's Test of Sphericity (Bartlett, 1950) were conducted. The KMO value of 0.691 and a significant Bartett's test $(p<0.05)$ indicated the adequacy of the correlation matrix for PCA. PCA was conducted on the full 55 items of Sheldon and Epstein's (2007) parent survey. In order to determine the number of components to extract, a threshold of eigenvalues greater than one was used as is often recommended (Kaiser, 1960; Costello and Osborne, 2005). Initially, nine components were extracted but after reviewing the scree plot along with item loadings, seven components were retained as this solution provided the best fit to the data. The coefficient threshold used to determine which items formed part of a component was set at 0.50 (Costello and Osborne, 2005). The eigenvalues of the seven components ranged from 1.61 to 7.95 and in combination explained $62.82 \%$ of the total variance in responses.

Sixteen items with cross-loadings were removed. Items with cross-loading are typically removed to facilitate component interpretation. However, an exception was made to temporarily retain one item that would have otherwise been removed due to cross-loadings. This decision was made to see how it might be interpreted in the rotated solution. Item 3j, shown in Table 1 (How often do you ask your child what he/she is learning in math), was retained. Unlike other cross-loaded items (e.g., "How often do you ask your child how well he/she is doing in school"), item $3 \mathrm{j}$ was retained because it specifically reflected parental behavior in relation to children's math achievement. Table $\mathbf{1}$ shows the sample size (n), mean (M) and standard deviation
(SD) of all 55 items. Items with an asterisk $\left(^{*}\right)$ indicate those 39 that were retained.

Direct oblimin rotation was applied to the seven components resulting in sums of squares loadings ranging from 2.71 to 5.44. Table 2 shows the item loadings after rotation. All seven components had moderate to high levels of internal consistency, with Cronbach's alpha ranging from 0.68 to 0.89 (see Table 2). These alpha values are in the same range as those reported by Sheldon and Epstein (2007). The correlations among the seven components ranged from -0.03 to 0.24 . As mentioned previously, one item (i.e., 3j. How often do you ask your child about what he/she is learning in math?) had moderate crossloadings of 0.41 and 0.52 on two components ( 3 and 5). The item was retained with component 5 because it reflected a slightly higher loading and component 5 already included an "asking" item about learning in science.

A review of Table 2 shows the seven principal components along with the 39 survey items that loaded on the components. Figure 3 also shows a visual mapping of the components, survey sections and R-PIP model variables of interest. In discussion of the components, survey section names will be used instead of R-PIP model variable names to minimize ambiguity, and because the PCA was applied to sections of the parent survey to operationalize R-PIP model variables. However, in discussion of results from the path analysis, the R-PIP model variables will be used as examining the relationship among parental involvement behaviors is guided by the R-PIP model.

As shown in Table 2, the 39 survey items loaded in consistent "chunks" to the components. In other words, the PCA revealed the survey's reliable structure in this Canadian sample. For example, component 1 was associated with the loading of section 5 items (Parents' beliefs about their capability in helping with children's education). Likewise, component 2 was associated with the loading of section 2 items (Parents' attitudes about the school and teachers in general). Component 6 revealed the loading of section 4 items (Parents' beliefs about their responsibility in children's education). Components 3 and 5 were associated with section 3 items (Parents' involvement behaviors). As well, components 4 and 7 were associated with section 1 items (Perceptions of teacher-parent contact).

A review of components 3 and 5 revealed a subtle difference in the nature of parental involvement items (section 3). For example, component 3 items reflected more active parental involvement (e.g., Help your child with math), whereas component 5 items reflected less active parental involvement (e.g., Ask your child about what he/she is learning in math?). Given this difference, component 3 was retained as providing a better measure of active parental involvement for the subsequent path analysis. A similar review of components 4 and 7 ensued. Again, a subtle difference in section 1 items was noted. Component 4 items reflected academic forms of parent-teacher contact (e.g., Helps me understand my child's stage of development), whereas component 7 items reflected non-academic forms of parent-teacher contact (e.g., Asks me to volunteer at the school). Component 4 was retained as providing a more relevant measure of parent-teacher contact for children's achievement and therefore used for the subsequent path analysis. Scale scores of parent participants were computed 
TABLE 2 | Direct oblimin rotation loadings of parental involvement survey items (all seven components shown).

Component 1: Parental Self-Efficacy ( $\alpha=0.86$ ) *

5a. I know how to help my child do well in school.

$5 \mathrm{~b}$. I never know if I'm getting through to my child.

$5 \mathrm{c}$. I know how to help my child make good grades in school.

0.77

5 d. I can motivate my child to do well in school.

5 e. I feel good about my efforts to help my child learn.

5f. I don't know how to help my child on schoolwork.

$-0.72$

$5 \mathrm{~g}$. My efforts to help my child learn are successful.

5h. I make a difference in my child's school performance.

Component 2: Parental Perceptions of General School Invitations $(\alpha=0.88$ ) *

2a. This is a very good school.

2b. I feel welcome at the school.

2c. I get along well with my child's teacher(s).

2d. The teachers at this school care about my child.

Component 3: Parental Involvement Behaviors $(\alpha=0.83)$

How often do you...

3a. Read with your child?

3d. Review and discuss the schoolwork your child brings home?

3 e. Help your child with math?

0.66

3f. Visit your child's school?

0.57

$3 \mathrm{~g}$. Go over spelling or vocabulary with your child?

0.69

3i. Talk to your child's teacher?

0.59

3k. Help your child with reading/language arts homework?

0.79

3q. Check to see if your child finished his/her homework?

Component 4: Parental Perceptions of Specific Teacher Invitations $(\alpha=0.89)$ *

My child's teacher or someone at the school...

1a. Helps me understand my child's stage of development.

1b. Tells me how my child is doing at school.

1f1. Tells me what skills my child needs to learn in: math.

0.87

1f2. Tells me what skills my child needs to learn in: reading/language arts

0.83

1f3. Tells me what skills my child needs to learn in: science

Component 5: Parents' Involvement Behaviors $(\alpha=0.84)$ *

How often do you...

3c. Work with your child on science homework?

3h. Ask your child about what he/she is learning in science?

3j. Ask your child about what he/she is learning in math?

31. Help your child understand what he/she is learning in science?

$3 \mathrm{~m}$. Help your child prepare for math tests?

Component 6: Parental role construction $(\alpha=0.76)$ *

It is a parent's responsibility to...

4a. Make sure that their child learns at school.

4b. Teach their child to value schoolwork.

4d. Contact the teacher as soon as academic problems arise.

4f. Keep track of their child's progress in school.

4j. Know if their child is having trouble in school.

1c. Asks me to volunteer at the school.

1g. Provides information on community services that I may want to use with my 


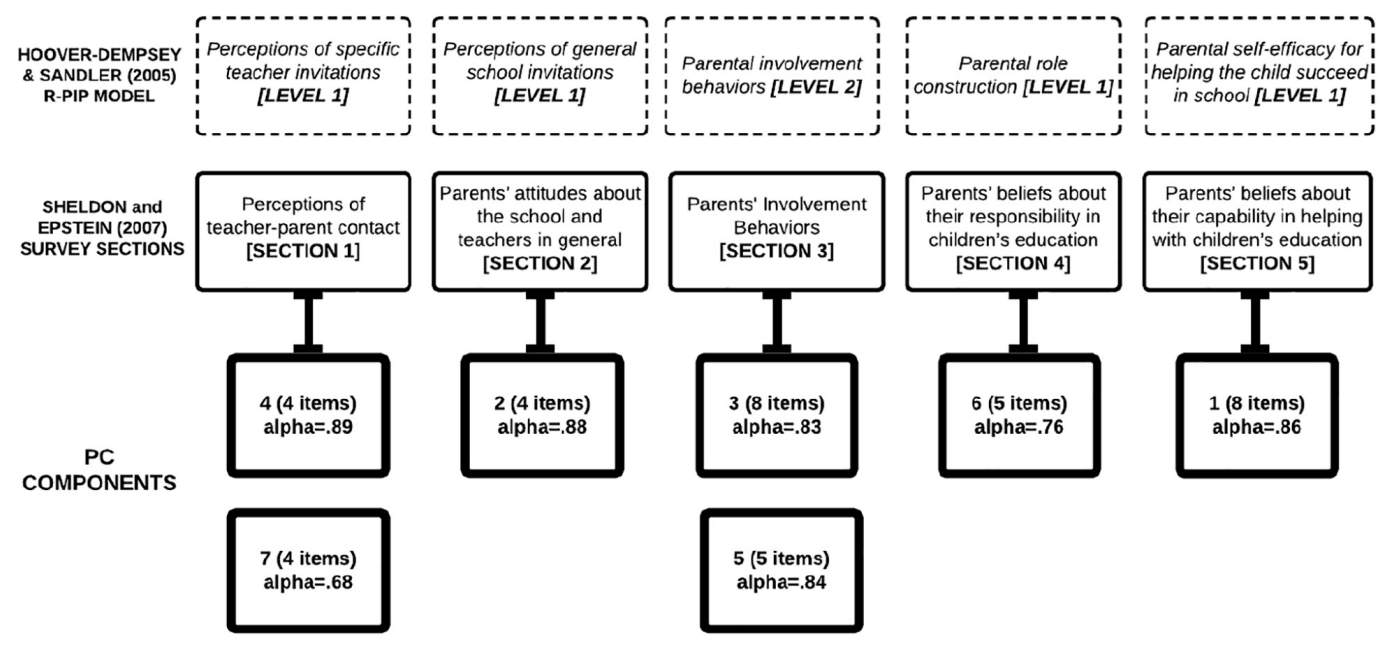

FIGURE 3 | Mapping of Hoover-Dempsey and Sandler (2005) R-PIP model in top Row, Sheldon and Epstein (2007) survey section in middle row with principal components (PC) in bottom row.

for five components (1, 2, 3, 4, and 6). Component scale scores were calculated by taking the mean of item scores loading on a particular component. For example, a parent's ratings of "3," “4," " 3 ," and " 4 " would have a mean of 3.5 or within the range of "Agree" and "Strongly Agree."

\section{Path Analysis}

Three path models were tested in order of plausibility. The first model is shown in Figure 4 and it provided the best fit to the parent-child data. This model illustrates component 2, which operationalizes the R-PIP's parental perception of general school invitations (Level 1 variable), as predictive of component 4, parental perception of teacher invitations (also Level 1 in R-PIP). In turn, component 4, which operationalizes the R-PIP's parental perception of specific teacher invitations, is shown to be predictive of component 1, parental self-efficacy for helping the child succeed in school (also Level 1 in R-PIP). Component 1, which operationalizes parental self-efficacy is shown to predict children's math achievement (Level 5 in the R-PIP model). In addition to these direct relationships, component 1 (parental selfefficacy for helping the child succeed in school) was hypothesized to directly affect component 6, which operationalizes role construction beliefs (Level 1 of the R-PIP model) and component 2, parental involvement behaviors (Level 2 of the R-PIP model). In turn, component 2 (parental involvement behaviors) was expected to directly influence children's math achievement. This first model yielded the best overall model-data fit considering the fit statistics recommended for path analysis: $\chi^{2}=10.08$, $\mathrm{df}=8, p=0.26(\mathrm{CFI}=0.967$; TLI $=0.938, \mathrm{SRMR}=0.050$; RMSEA $=0.043,90 \%$ CI $[0.000,0.114])$. The ratio of $\chi^{2}$ to the df was 1.26. A ratio value of three or less reflects reasonably good indicator of model fit (Kline, 2016).

A second and third model were also tested for comparison. The second model was very similar to the first except that the variable of parental role construction beliefs was used to predict parental self-efficacy (instead of the other way around as in the first model). The use of parental role construction beliefs to predict parental self-efficacy was considered because it is conceivable that beliefs could be a driver of a perceived sense of ability. However, the model-data fit was poor relative to the first model as evidenced by the fit indices: $\chi^{2}=14.89$, $\mathrm{df}=8, p=0.06$ (CFI $=0.895$; TLI $=0.816$, SRMR $=0.074$; RMSEA $=0.079,90 \%$ CI $[0.000,0.141])$. The third model was also similar to the first model except the variable of parental perceptions of specific teacher invitations was used to predict perceptions of general school invitations (instead of the other way around as in the first model). The testing of whether perceptions of specific teacher invitations could be predictive of perceptions of school invitations was considered because it is conceivable that particular experiences with teachers could be generalized by parents to extend to how they view the school broadly. However, again the model-data fit was poor relative to the first model: $\chi^{2}=14.73$, df $=8, p=0.06(\mathrm{CFI}=0.888$; TLI $=0.789$, SRMR $=0.072$; RMSEA $=0.078,90 \%$ CI $[0.000,0.139])$.

Only statistically significant effects are shown in Figure 4. The standardized coefficients of the best-fitting model indicated that parental perceptions of general school invitations positively predicted perceptions of specific teacher invitations $(\beta=0.285$, $S E=0.122, p<0.05)$. In turn, perceptions of specific teacher invitations positively predicted parental self-efficacy $(\beta=0.251$, $S E=0.083, p<0.01)$, which in turn positively predicted parental involvement behaviors toward children $(\beta=0.188, S E=0.094$, $p<0.05)$ and parental role construction $(\beta=0.465, S E=0.073$, $p<0.001)$. Interestingly, whereas parental involvement behaviors negatively predicted children's math achievement $(\beta=-0.269$, $S E=0.101, p<0.01)$, parental role construction beliefs did not directly predict children's math achievement. Moreover, the path between parental role construction and parental involvement behaviors was not statistically significant. The only variable that positively and directly predicted children's math achievement was parental self-efficacy for helping the child succeed $(\beta=0.276, S E=0.087, p=0.001)$. In the path model, almost all the standardized coefficients were found to be statistically significant, indicating strong relations among the 


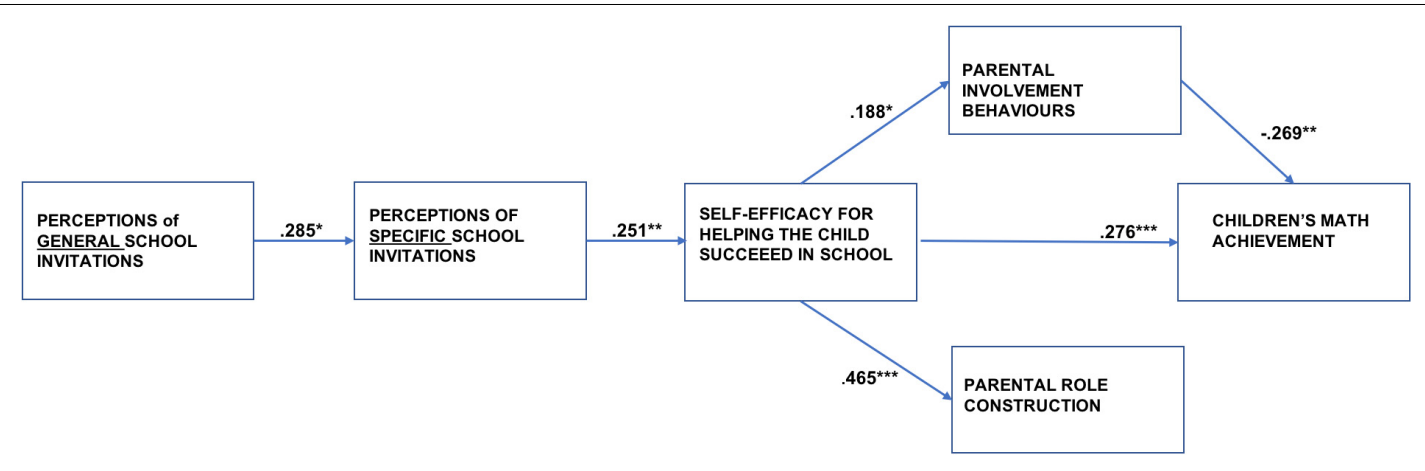

FIGURE 4 | Path model for statistically significant effects of parental involvement factors on children's mathematics achievement. The direct effects between Role Construction and Involvement Behaviors was tested but not significant. Likewise, the effect between Role Construction and Children's Math Achievement. ${ }^{\star} p<0.05,{ }^{\star \star} p<0.01,{ }^{* \star *} p<0.001$

components. Observed correlations among components were ranged from -0.03 to 0.24 .

As can be seen in Figure 4, there were several mediating variables in the pathway model, indicating indirect effects. The bias-corrected (BC) bootstrap approach with confidence interval (estimator = maximum likelihood, with 1000 bootstrap; Geiser, 2010) was used to test indirect effects given the small sample size (MacKinnon et al., 2002). An indirect effect is considered statistically significant at the 0.05 level if the $95 \%$ BC bootstrap confidence interval does not include zero (MacKinnon, 2008). Table 3 shows the systematic testing of specific indirect effects, as well as the $95 \%$ biascorrected (BC) bootstrap confidence intervals (CI). The raw coefficients indicated statistically significant indirect effects between perceptions of general school invitations and children's math achievement for up to four mediators (i.e., perceptions of specific teacher invitations, parental selfefficacy, parental role construction, and parents' involvement behaviors; $\beta=-0.003,95 \%$ CI $[-0.018,-0.001])$. However, the standardized coefficients of these three indirect pathways were not significant $(\beta=0.02,95 \%$ CI $[-0.01,0.049 ; \beta=-0.004$, 95\% CI [-0.011, 0.004]; $\beta=-0.001,95 \%$ CI [-0.004, 0.001]). According to Muthen (2009), when there are inconsistencies between raw and standardized coefficients, confidence intervals of raw coefficients should be reported. These non-significant standardized results are often the result of small sample size differences.

Overall, the R-Square index showed that the best-fitting model shown in Figure 4 explained 6.3\% of the variance in parental selfefficacy, $8.1 \%$ of the variance in perceptions of specific teacher invitations, and $9.1 \%$ of the variance in parents' involvement behaviors. Finally, the hypothesized model accounted for $21.6 \%$ of the variance of parental role construction beliefs and $10.9 \%$ of the variance of children's math achievement.

\section{DISCUSSION}

Guided by Hoover-Dempsey and Sandler's (2005) R-PIP model, the following research questions were investigated: What is the internal structure of the Sheldon and Epstein (2007) Parent Survey of Family and Community Involvement in Elementary and Middle Grades in the sample of parents of included in the present study? What is the most parsimonious path model for explaining relationships among variables such as parental beliefs, perceptions and involvement in children's math achievement. The Sheldon and Epstein (2007) survey was used to operationalize the variables in the R-PIP model.

Based on a PCA with direct oblimin rotation, seven components were extracted from the Sheldon and Epstein (2007) survey, which operationalized Level 1 and 2 variables in the R-PIP model. All seven components indicated moderate to high internal consistency. Hence, the PCA analysis provided general support not only for the internal structure of the Parent Survey of Family and Community Involvement in Elementary and Middle Grades (Sheldon and Epstein, 2007) but also for variables outlined in the R-PIP model. Furthermore, the path analysis showed that one model provided a better account than two others in accounting for the relationship between parental beliefs, perceptions and involvement in children's math achievement. Parents' perceptions of general school invitations predicted their perceptions of specific teacher invitations. In turn, perceptions of specific teacher invitations positively predicted parental selfefficacy beliefs. Parental sense of self-efficacy was found to be a positive predictor of their role construction beliefs and specific involvement behaviors in their children's learning. These results supported the working hypothesis that invitations from important others at school may contribute significantly to the increase in parental self-efficacy and role construction beliefs in children's math achievement (Hoover-Dempsey et al., 2005).

Congruent with the R-PIP model (Hoover-Dempsey and Sandler, 1995, 1997, 2005), the results indicate evidence of the positive relationship of Level 1 and Level 2 variables with Level 5 variables. In particular, the results show that Level 1 variables such as parental perceptions of general school invitations, specific teacher invitations and self-efficacy positively predict children's mathematics achievement. Moreover, parental selfefficacy contributed directly to parental involvement behaviors such as reading, reviewing, and helping children with homework (see items in Table 2 used to operationalize parental involvement 
TABLE 3 | Raw (R) and standardized (S) coefficients of indirect effect estimates of parents' perceptions of general school invitations on children's math achievement.

\begin{tabular}{|c|c|c|c|}
\hline Predictor & Mediating variables (s) & Criterion & Coefficient estimate $(95 \% \mathrm{Cl})$ \\
\hline \multirow[t]{2}{*}{$\begin{array}{l}\text { Perception of General } \\
\text { School Invitations } \rightarrow\end{array}$} & $\begin{array}{l}\text { Perception of Specific Teacher Invitation } \rightarrow \text { Parental } \\
\text { Self-efficacy } \rightarrow\end{array}$ & Math achievement & $0.039(0.006,0.122)^{\star}(R)$ \\
\hline & & & $0.020(-0.010,0.049)(\mathrm{S})$ \\
\hline \multirow[t]{2}{*}{$\begin{array}{l}\text { Perception of General } \\
\text { School Invitations } \rightarrow\end{array}$} & $\begin{array}{l}\text { Perception of Specific Teacher Invitation } \rightarrow \text { Parental } \\
\text { Self-efficacy } \rightarrow \text { Parental Involvement Behaviors } \rightarrow\end{array}$ & Math achievement & $-0.007(-0.035,-0.001)^{\star}(R)$ \\
\hline & & & $-0.004(-0.011,0.004)(\mathrm{S})$ \\
\hline \multirow{3}{*}{$\begin{array}{l}\text { Perception of General } \\
\text { School Invitations } \rightarrow\end{array}$} & Perception of Specific Teacher Invitation $\rightarrow$ Parental & Math achievement & $-0.003(-0.018,-0.001)^{\star}(\mathrm{R})$ \\
\hline & $\begin{array}{l}\text { Self-efficacy } \rightarrow \text { Role Construction } \rightarrow \text { Parental Involvement } \\
\text { Behaviors } \rightarrow\end{array}$ & & \\
\hline & & & $-0.001(-0.004,0.001) \quad(S)$ \\
\hline
\end{tabular}

Numbers in parentheses represent $95 \%$ bias-corrected bootstrap confidence intervals. *95\% confidence interval excludes zero and therefore is significant at $p<0.05$.

behaviors). Although the R-PIP model does not specify the direction of relationships among Level 1 variables, the present study found a sequence of influences at this level: stemming from parental perceptions of general school invitations, to perceptions of specific teacher invitations to parental self-efficacy. This sequence of influence is consistent with previous research (Hoover-Dempsey et al., 2005).

The present study also extended support of the R-PIP model with evidence that parental self-efficacy mediates the relationship between parental perceptions of general school invitations, specific teacher invitations and parental involvement behaviors, which sits as a Level 2 variable in the R-PIP model. Parental self-efficacy, more so than parental role construction beliefs, was shown to be predictive of parental involvement in children's schooling (Hoover-Dempsey and Sandler, 1997; Walker et al., 2005). Overall, these results suggest that when parents perceive the school as generally inviting, this overall perception may create a frame for enhancing their perceptions of specific teacher invitations. These positive perceptions may reliably enhance parental self-efficacy for helping their children achieve in math.

Another directional influence found between Level 1 variables was from parental self-efficacy to help children succeed toward parental role construction beliefs. This directional influence suggests that parents who are confident in their ability to help children succeed may cultivate stronger beliefs about their role and responsibility in children's math achievement. Interestingly, however, the relationship between role construction (beliefs) and involvement behaviors (action) was not statistically significant. The lack of statistical significance is not wholly unexpected as investigators have found that conscious thought or beliefs are not necessarily a good predictor of action (Masicampo and Baumeister, 2013). For example, Masicampo and Baumeister (2013) review the literature on the link between conscious or explicit thought such as those beliefs that parents might report on a survey and the likelihood that those thoughts will actually guide action such as helping behaviors. Masicampo and Baumeister (2013) indicate that, in fact, there is more evidence that implicit thought, which often includes subtle environmental influences (e.g., time, energy) and social motives (e.g., competition with other parents), is the real driver of action. Often implicit thought is laden with emotions such as in affective priming effects (see Klauer and Musch,
2003). Thus, consciously believing something to be the case may be insufficient to energize action unless it is also accompanied with commensurate implicit thoughts and emotions. In this respect, it may be more effective to first instill in parents an emotional connection in seeing themselves as contributing to their children's success, and second an intellectual connection.

Although parental self-efficacy was found to be a positive predictor of children's math achievement, the effect was direct and not indirect as indicated in the R-PIP model. This discrepancy, however, may be attributed to the constraints of the present research as Level 3 and 4 variables were not measured in the sample of parents. Thus, they could not be included in the path model. In fact, one would expect an indirect effect of parental self-efficacy on children's achievement. Previous research has shown that parents who have high selfefficacy may be more likely to engage in interactions that facilitate children's math achievement indirectly such as holding higher expectations for their children (e.g., Ginsburg-Block et al., 2010) and reducing their math anxiety (Vukovic et al., 2013). Furthermore, in support of the R-PIP model, a direct effect was found between a higher-level variable-parental involvement behaviors-and children's math achievement. However, it is important to note that this effect was negative. The real challenge may be to find relationship between distal variables such as Level 1 (e.g., parental perceptions of general school invitations and parental self-efficacy) and Level 5 (children's math achievement), and not proximal variables such as Level 4 (children's attributes that lead to achievement) and Level 5 (children's achievement).

The negative association between parental involvement behaviors and children's math achievement is also consistent with previous research (Jeynes, 2005; Patall et al., 2008; Hill and Tyson, 2009). In fact, Fishel and Ramirez (2005) in a review of the literature indicated that evidence-based parental involvement in children's academic performance is inconclusive thus far because of methodological weaknesses in studies investigating how parents actually become involved in children's schooling. Although parents might engage in involvement behaviors with very good intentions, these behaviors may not be effective or appropriate (Wilder, 2014). For example, the quality of parental homework assistance has been found to be more 
important than its frequency in children's academic development (Pomerantz et al., 2007). It is also the case that children who struggle academically may need more involvement from parents (Silinskas et al., 2013; Wilder, 2014). Alternatively, parents' involvement behaviors may inadvertently lower children's autonomy and self-directed motivation, and result in children developing negative perceptions about themselves, which in turn may negatively affect their academic achievement (e.g., Cooper et al., 2000; Dumont et al., 2012; Moroni et al., 2015; Moè et al., 2020). For example, when children perceive parents as interfering and controlling, parental help may be negatively correlated with students' achievement. Moè et al. (2020) showed that even a brief but targeted intervention in supporting parental needs can help lower stress and encourage the adoption of practices that were better suited to helping children academically. In other words, the take home message here is that more parental involvement may not necessarily be better if it is not well-suited (Pomerantz et al., 2007). Instead, more parental self-efficacy may be better to help parents support their children in acquiring the autonomy to take responsibility for their achievement. This is the reason why Level 3 and 4 variables in the R-PIP model should be investigated in future research.

Before concluding this section, it is important to note that although path model raw coefficients were statistically significant, the observed correlations among components were generally weaker. This incongruence may be explained by the use of listwise deletion in PCA to handle missing data. When listwise deletion is used, the data from a participant with even one missing item response are removed fully from consideration. This leads to the loss of information (and variation) in the calculation of individual correlations among components. However, in path analysis, scale score means can be computed with part information, allowing additional power in detecting significant relationships.

\section{Implications}

The present study has both theoretical and practical implications. Theoretically, this study was able to evaluate the interplay of variables in the R-PIP model (Hoover-Dempsey and Sandler, 1995, 1997, 2005). The results provide evidence for the R-PIP model by showing significant mediating relationships between parental perceptions and children's math achievement via parental self-efficacy, parental role construction, and parental involvement in children's schoolwork. These results add support to previous research on intervention work designed to help parents enhance their support of children's academic learning (e.g., Patall et al., 2008; Froiland, 2011; Mabbe et al., 2018; Moè and Katz, 2018; Moè et al., 2018). From a pragmatic perspective, moreover, the internal structure of Sheldon and Epstein's (2007) parent survey provided evidence for the reliability and internal structure of the parental involvement process in the sample of parents included in this study. Specifically, school professionals may find it beneficial to use such a parent survey to collect feedback about how parents perceive the school and to inform the design of programs to foster a more inviting school environment. A positive change in how welcoming parents perceive the school may lead to a boost in their self-efficacy for getting involved directly in their children's academic life.

\section{Limitations}

The results of this study need to be considered in light of the following limitations. First, the present study involved a relatively small sample of convenience. Participants came from one elementary school in a moderately large city in Western Canada. Therefore, generalization of results must be limited to the specific attributes of the sample. In addition, the size of sample is likely to have contributed to the discrepancy in statistical significance between raw and standardized coefficients for the indirect effects found in the path model. Second, the use of a survey (Sheldon and Epstein, 2007) to collect self-report data can present potentially biased responses (Duckworth and Yeager, 2015). Third, children's math achievement was not based on standardized measures but teachers' classroom assessments, which may not be an unbiased reflection of students' achievement. Fourth, the survey data were cross-sectional, without accounting for the effects of several moderating variables (e.g., SES, ethnicity). The challenge with including these variables in the present sample was that the sample composition was relatively homogeneous, with a majority identifying as European-White (Caucasian) (69.1\%) and speaking English at home (85.6\%). In addition, there were no significant differences between parental education levels in survey scale scores. Finally, the present study focused on only some of the variables in the R-PIP model. Understandably, school leaders cautioned against administering long surveys to parents, so decisions needed to be made about which variables to measure. Thus, some data were not asked of parent or children. Due to these limitations, the results from the present study need to be extended in light of other studies about parental involvement in connection to their children's achievement.

\section{Directions for Future Research}

Future studies regarding parental involvement and children's academic achievement should continue to explore the Levels of the R-PIP model, and attempt to include Levels 3 and 4. For example, collecting data about children's perceptions of parents' involvement behaviors to examine how well these data correlate with parental reports. Another important area for future research is examining the connection between aspects of self-efficacy for informing parental beliefs about getting involved in their children's academic life. What makes this area fascinating is that low-confidence parents are likely modeling low-confidence to their children, and this lack of confidence is likely to discourage children's academic attainment. The negative association between parental involvement behaviors and math achievement also deserves study. Investigating the quality of and mechanisms underlying the verbal and behavioral strategies parents use to help children with schoolwork may illuminate detrimental effects. For example, if homework conversations are contentious, this may be harmful to both children and parents. Additionally, different subject areas need to be considered as outcome variables (e.g., math, science, language arts) in future studies with larger sample sizes, thus providing more comprehensive understanding 
of the influence of parental involvement behaviors on children's academic achievement.

\section{DATA AVAILABILITY STATEMENT}

The raw data supporting the conclusions of this article will be made available by the authors, without undue reservation.

\section{ETHICS STATEMENT}

The studies involving human participants were reviewed and approved by the Human Ethics Research Office (HERO) Pro00032355. Written informed consent to participate in this study was provided by the participants or participants' legal guardian/next of kin where necessary.

\section{REFERENCES}

Bandura, A. (1997). Self-Efficacy: The Exercise of Control. New York, NY: Freeman. Bartlett, M. S. (1950). Tests of significance in factor analysis. Br. J. Math. Stat. Psychol. 3, 77-85. doi: 10.1111/j.2044-8317.1950.tb00285.x

Beavers, A. S., Lounsbury, J. W., Richards, J. K., Huck, S. W., Skolits, G. J., and Esquivel, S. L. (2013). Practical considerations for using exploratory factor analysis in educational research. Pract. Assess. Res. Eval. 18:6.

Boonk, L., Gijselaers, H. J., Ritzen, H., and Brand-Gruwel, S. (2018). A review of the relationship between parental involvement indicators and academic achievement. Educ. Res. Rev. 24, 10-30. doi: 10.1016/j.edurev.2018.02.001

Carmichael, C., and MacDonald, A. (2016). Parental influences on primary school children's mathematics achievement: insights from the Longitudinal Study of Australian Children. Education 44, 197-211. doi: 10.1080/03004279.2014. 939684

Castro, M., Expósito-Casas, E., López-Martín, E., Lizasoain, L., Navarro-Asencio, E., and Gaviria, J. L. (2015). Parental involvement on student academic achievement: a meta-analysis. Educ. Res. Rev. 14, 33-46.

Coleman, P. K., and Karraker, K. H. (1998). Self-efficacy and parenting quality: findings and future applications. Dev. Rev. 18, 47-85. doi: 10.1006/drev.1997. 0448

Cooper, H., Lindsay, J. J., and Nye, B. (2000). Homework in the home: how student, family, and parenting-style differences relate to the homework process. Contemp. Educ. Psychol. 25, 464-487. doi: 10.1006/ceps.1999.1036

Costello, A. B., and Osborne, J. (2005). Best practices in exploratory factor analysis: four recommendations for getting the most from your analysis. Pract. Assess. Res. Eval. 10, 1-9.

Deci, E. L., and Ryan, R. M. (2008). Self-determination theory: a macrotheory of human motivation, development, and health. Can. Psychol. 49, 182-185. doi: 10.1037/a0012801

Driessen, G., Smit, F., and Sleegers, P. (2005). Parental involvement and educational achievement. Br. Educ. Res. J. 31, 509-532. doi: 10.1080/ 01411920500148713

Duckworth, A. L., and Yeager, D. S. (2015). Measurement matters: assessing personal qualities other than cognitive ability for educational purposes. Educ. Res. 44, 237-251. doi: 10.3102/0013189x15584327

Dumont, H., Trautwein, U., Lüdtke, O., Neumann, M., Niggli, A., and Schnyder, I. (2012). Does parental homework involvement mediate the relationship between family background and educational outcomes? Contemp. Educ. Psychol. 37, 55-69. doi: 10.1016/j.cedpsych.2011.09.004

Duncan, G. J., Dowsett, C. J., Claessens, A., Magnuson, K., Huston, A. C., Klebanov, P., et al. (2007). School readiness and later achievement. Dev. Psychol. 43, 1428-1446.

Enders, C. K. (2010). Applied Missing Data Analysis. New York: Guilford Press.

\section{AUTHOR CONTRIBUTIONS}

YL wrote the first draft and conducted the analyses. JL revised all subsequent drafts and all parts of the manuscript, and reviewed appropriateness of analyses, and reworked all figures. Both authors contributed to the article and approved the submitted version.

\section{FUNDING}

Preparation of this paper was supported by a grant to the second author from the Social Sciences and Humanities Research Council of Canada (SSHRC Grant No. 435-2016-0114). Grantees undertaking such projects are encouraged to express freely their professional judgment. This paper, therefore, does not necessarily represent the positions or the policies of the Canadian government, and no official endorsement should be inferred.

Epstein, J. L., Sanders, M. G., Sheldon, S., Simon, B. S., Salinas, K. C., Jansorn, N. R., et al. (2019). School, Family and Community Partnerships: Your Handbook for Action, Fourth Edition. Thousand Oaks, CA: Corwin.

Fan, X., and Chen, M. (2001). Parental involvement and students' academic achievement: a meta-analysis. Educ. Psychol. Rev. 13, 1-22.

Fishel, M., and Ramirez, L. (2005). Evidence-based parent involvement interventions with school-aged children. Sch. Psychol. Q. 20, 371-402. doi: 10.1521/scpq.2005.20.4.371

Froiland, J. M. (2011). Parental autonomy support and student learning goals: a preliminary examination of an intrinsic motivation intervention. Child Youth Care Forum 40, 135-149. doi: 10.1007/s10566-010-9126-2.1007/s11031-0149423-4

Geiser, C. (2010). Data analysis with Mplus. New York, NY: The Guildford Press. Ginsburg-Block, M., Manz, P. H., and McWayne, C. (2010). "Partnering to foster achievement in reading and mathematics," in Handbook of School-Family Partnerships, eds S. Christenson and A. Reschly (New York, NY: Routledge), 175-203.

Hill, N. E., Castellino, D. R., Lansford, J. E., Nowlin, P., Dodge, K. A., Bates, J. E., et al. (2004). Parent academic involvement as related to school behavior, achievement, and aspirations: demographic variations across adolescence. Child Dev. 75, 1491-1509. doi: 10.1111/j.1467-8624.2004. 00753.x

Hill, N. E., and Tyson, D. F. (2009). Parental involvement in middle school: a metaanalytic assessment of the strategies that promote achievement. Dev. Psychol. 45:740. doi: $10.1037 / \mathrm{a} 0015362$

Hoover-Dempsey, K., Walker, J. M. T., Sandler, H. M., Whetsel, D., Green, C. L., Wilkins, A. S., et al. (2005). Why do parents become involved? Research findings and implications. Element. Sch. J. 106, 105-130. doi: 10.1086/49 9194

Hoover-Dempsey, K. V., and Sandler, H. M. (1995). Parental involvement in children's education: why does it make a difference? Teach. Coll. Rec. 97, 310-331.

Hoover-Dempsey, K. V., and Sandler, H. M. (1997). Why do parents become involved in their children's education? Rev. Educ. Res. 67, 3-42. doi: 10.3102/ 00346543067001003

Hoover-Dempsey, K. V., and Sandler, H. M. (2005). The Social Context of Parental Involvement: A Path to Enhanced Achievement. Final report for the Office of Educational Research and Improvement (Grant No. R305T010673). Washington, DC: U.S. Department of Education.

Hornby, G. (2011). Parental Involvement in Childhood Education. New York, NY: Springer.

Jeynes, W. H. (2005). A meta-analysis of the relation of parental involvement to urban elementary school student academic achievement. Urban Educ. 40, 237-269. doi: 10.1177/0042085905274540 
Johnson, U. Y., and Hull, D. M. (2014). Parent involvement and science achievement: a cross-classified multilevel latent growth curve analysis. J. Educ. Res. 107, 399-409. doi: 10.1080/00220671.2013.807488

Joussemet, M., Landry, R., and Koestner, R. (2008). A self-determination theory perspective on parenting. Can. Psychol. 49, 194-200. doi: 10.1037/a0012754

Kaiser, H. (1970). A second generation little jiffy. Psychometrika 35, 401-415. doi: $10.1007 / \mathrm{bf} 02291817$

Kaiser, H. F. (1960). The application of electronic computers to factor analysis. Educ. Psychol. Meas. 20, 141-151. doi: 10.1177/001316446002000116

Klauer, K. C., and Musch, J. (2003). "Affective priming: findings and theories," in The Psychology of Evaluation: Affective Processes in Cognition and Emotion, eds J. Musch and K. C. Klauer (Mahwah, NJ: Erlbaum), 9-50.

Kline, R. B. (2016). Principles and Practice of Structural Equation Modeling, 4th Edn. New York: The Guilford Press.

LaRocque, M., Kleiman, I., and Darling, S. M. (2011). Parental involvement: the missing link in school achievement. Prevent. Sch. Fail. 55, 115-122. doi: 10. 1080/10459880903472876

Lee, J. S., and Bowen, N. K. (2006). Parent involvement, cultural capital, and the achievement gap among elementary school children. Am. Educ. Res. J. 43, 193-218. doi: 10.3102/00028312043002193

Leighton, J. P. (2013). Interim Report \#2 on Research Project for Suzuki Charter School: Initial Parent and Teacher Data and Findings. Edmonton: University of Alberta.

Leighton, J. P., Guo, Q., Chu, M., and Tang, W. (2018). A pedagogical alliance for academic achievement: socio-emotional effects on assessment outcomes. Educational Assessment 23, 1-23. doi: 10.1080/10627197.2017.1411188

Liu, G., Zhang, S., Zhang, J., Lee, C., Wang, Y., and Brownell, M. (2013). Autonomous motivation and Chinese adolescents' creative thinking: the moderating role of parental involvement. Creat. Res. J. 25, 446-456. doi: 10. 1080/10400419.2013.843401

Ma, X., Shen, J., Krenn, H. Y., Hu, S., and Yuan, J. (2016). A meta-analysis of the relationship between learning outcomes and parental involvement during early childhood education and early elementary education. Educ. Psychol. Rev. 28, 771-801. doi: 10.1007/s10648-015-9351-1

Mabbe, E., Soenens, B., Vansteenkiste, M., van der Kaap-Deeder, J., and Mouratidis, A. (2018). Day-to-day variation in autonomy-supportive and psychologically controllingparenting: the role of parents' daily experiences of need satisfaction and need frustration. Parenting 18, 86-109. doi: 10.1080/15295192.2018. 1444131

MacKinnon, D. P. (2008). Introduction to Statistical Mediation Analysis. New York, NY: Erlbaum.

MacKinnon, D. P., Lockwood, C. M., Hoffman, J. M., West, S. G., and Sheets, V. (2002). A comparison of methods to test mediation and other intervening variable effects. Psychol. Methods 7, 83-104. doi: 10.1037/1082-989x.7.1.83

Masicampo, E. J., and Baumeister, R. F. (2013). Conscious thought does not guide moment-to-moment actions-it serves social and cultural functions. Front. Psychol. 4:478. doi: 10.3389/fpsyg.2013.00478

McBride, B. A., Dyer, W. J., Liu, Y., Brown, G. L., and Hong, S. (2009). The differential impact of early father and mother involvement on later student achievement. J. Educ. Psychol. 101, 498-508. doi: 10.1037/a0014238

Moè, A., and Katz, I. (2018). Brief research report: parents' homework emotions favor students' homework emotions through self-efficacy. J. Exp. Educ. 86, 597-609. doi: 10.1080/00220973.2017.1409180

Moè, A., Katz, I., and Alesi, M. (2018). Scaffolding for motivation by parents, and child homework motivations and emotions: effects of a training programme. $\mathrm{Br}$. J. Educ. Psychol. 88, 323-344. doi: 10.1111/bjep.12216

Moè, A., Katz, I., Cohen, R., and Alesi, M. (2020). Reducing homework stress by increasing adoption of need-supportive practices: effects of an intervention with parents. Learn. Individ. Diff. 82:101921. doi: 10.1016/j.lindif.2020.10 1921

Moroni, S., Dumont, H., Trautwein, U., Niggli, A., and Baeriswyl, F. (2015). The need to distinguish between quantity and quality in research on parental involvement: the example of parental help with homework. J. Educ. Res. 108, 417-431. doi: 10.1080/00220671.2014.901283
Muthen, B. O. (2009). CIs: Unstandardized vs. Standardized (Mplus Discussion Forum). Available online at: http://www.statmodel.com/discussion/messages/ 11/4331.html?1426677590 (accessed August 1, 2019). doi: 10.1080/00220671. 2014.901283

Muthen, B. O., and Asparouhov, T. (2002). Using Mplus Monte Carlo Simulations in Practice: A Note on Non-Normal Missing Data in Latent Variable Models. Los Angeles, CA: Muthen \& Muthen.

Muthen, L. K., and Muthen, B. O. (2013). Mplus User's Guide (Version 7.11.). Los Angeles, CA: Muthen \& Muthen.

Niehaus, K., Rudasill, K. M., and Rakes, C. R. (2012). A longitudinal study of school connectedness and academic outcomes across sixth grade. J. Sch. Psychol. 50, 443-460. doi: 10.1016/j.jsp.2012.03.002

Patall, E. A., Cooper, H., and Robinson, J. C. (2008). Parent involvement in homework: a research synthesis. Rev. Educ. Res. 78, 1039-1101. doi: 10.3102/ 0034654308325185

Pomerantz, E. M., Moorman, E. A., and Litwack, S. D. (2007). The how, whom, and why of parents' involvement in children's academic lives: more is not always better. Rev. Educ. Res. 77, 373-410. doi: 10.3102/003465430305567

Sheldon, S. B. (2002). Parents' social networks and beliefs as predictors of parent involvement. Element. Sch. J. 102, 301-316. doi: 10.1086/499705

Sheldon, S. B., and Epstein, J. L. (2005). Involvement counts: family and community partnerships and mathematics achievement. J. Educ. Res. 98, 196206. doi: 10.3200/joer.98.4.196-207

Sheldon, S. B., and Epstein, J. L. (2007). Parent Survey of Family and Community Involvement in the Elementary and Middle Grades. Baltimore: Johns Hopkins University.

Shumow, L., and Lomax, R. (2002). Parental efficacy: predictor of parenting behavior and adolescent outcomes. Parent. Sci. Pract. 2, 127-150. doi: 10.1207/ s15327922par0202_03

Sibley, E., and Dearing, E. (2014). Family educational involvement and child achievement in early elementary school for American-born and immigrant families. Psychol. Sch. 51, 814-831. doi: 10.1002/pits.21784

Silinskas, G., Niemi, P., Lerkkanen, M. K., and Nurmi, J. E. (2013). Children's pooxr academic performance evokes parental homework assistance-but does it help? Int. J. Behav. Dev. 37, 44-56. doi: 10.1177/0165025412456146

Stright, A. D., and Yeo, K. L. (2013). Maternal parenting styles, school involvement, and children's school achievement and conduct in Singapore. J. Educ. Psychol. 106, 301-314. doi: 10.1037/a0033821

Tam, V. C., and Chan, R. M. (2009). Parental involvement in primary children's homework in Hong Kong. Sch. Commun. J. 19, 81-100.

Veas, A., Castejón, J. L., Gilar, R., and Miñano, P. (2015). Academic achievement in early adolescence: the influence of cognitive and non-cognitive variables. J. Gen. Psychol. 142, 273-294. doi: 10.1080/00221309.2015.1092940

Vukovic, R. K., Roberts, S. O., and Green Wright, L. (2013). From parental involvement to children's mathematical performance: the role of mathematics anxiety. Early Educ. Dev. 24, 446-467. doi: 10.1080/10409289.2012.693430

Walker, J. M. T., Wilkins, A. S., Dallaire, J. R., Sandler, H. M., and HooverDempsey, K. (2005). Parental involvement: model revision through scale development. Element. Sch. J. 106, 85-104. doi: 10.1086/499193

Wang, J., and Wang, X. (2012). Structural Equation Modeling: Applications using Mplus. Chichester: Wiley/Higher Education Press.

Wilder, S. (2014). Effects of parental involvement on academic achievement: a meta-synthesis. Educ. Rev. 66, 377-397. doi: 10.1080/00131911.2013.780009

Conflict of Interest: The authors declare that the research was conducted in the absence of any commercial or financial relationships that could be construed as a potential conflict of interest.

Copyright (c) 2021 Liu and Leighton. This is an open-access article distributed under the terms of the Creative Commons Attribution License (CC BY). The use, distribution or reproduction in other forums is permitted, provided the original author(s) and the copyright owner(s) are credited and that the original publication in this journal is cited, in accordance with accepted academic practice. No use, distribution or reproduction is permitted which does not comply with these terms. 